\title{
Los trabajos de mujeres y menores en los ferrocarriles de la Argentina a comienzos del siglo XX
}

Resumen: Este artículo se propone examinar un aspecto poco conocido del mundo del trabajo ferroviario en la Argentina de comienzos del siglo XX, tal como fue la participación laboral de mujeres y menores. A partir de un corpus documental variado, busca conocer qué puestos ocupaban, cómo llegaban a estos y cuáles eran sus condiciones de trabajo. Se espera con ello poder recuperar la diversidad de experiencias obreras y relaciones de trabajo existentes en los ferrocarriles, las cuales implicaron una multiplicidad de prácticas, arreglos y modalidades laborales que exceden y complejizan su conceptualización como trabajo formal, asalariado y masculino.

Palabras clave: mujeres, menores, ferrocarriles, trabajo, Argentina.

\section{The work of women and minors in the railways of Argentina at the beginning of the 20th century}

Abstract: This article aims to examine a little-known aspect of the world of railway work in Argentina at the beginning of the 20th century, namely, the labor participation of women and minors. With a varied documentary corpus, it seeks to find out what positions they held, how they got there, and their working conditions. It hopes to recover the diversity of worker experiences and labor relations existing in the railways, implying a multiplicity of practices, arrangements, and labor modalities exceeding their conceptualization as formal, salaried, and male work.

Keywords: women, minors, railways, work, Argentina.

\section{O trabalho de mulheres e menores nas ferrovias da Argentina no início do século XX}

Resumo: Este artigo tem como objetivo examinar um aspecto pouco conhecido do mundo do trabalho ferroviário na Argentina no início do século XX, qual seja, a participação laboral de mulheres e menores. A partir de um corpus documental variado, busca-se saber quais postos ocuparam, como chegaram até eles e quais eram suas condições de trabalho. Com isso, espera-se resgatar a diversidade de experiências e de relações de trabalho existentes nas ferrovias, as quais implicaram uma multiplicidade de práticas, arranjos e modalidades de trabalho que extrapolam e complexificam sua conceituação como trabalho formal, assalariado e masculino. Palavras-chave: mulheres, menores, ferrovias, trabalho, Argentina.

Cómo citar este artículo: Florencia D’Uva, "Los trabajos de mujeres y menores en los ferrocarriles de la Argentina a comienzos del siglo XX", Trashumante. Revista Americana de Historia Socia/18 [2021]: 146-167.

DOI: 10.17533/udea.trahs.n18a07

\section{Fecha de recepción: 8 de septiembre de 2020}

Fecha de aprobación: 10 de diciembre de 2020

Florencia D’Uva: Doctora en Historia por la Universidad de Buenos Aires. Becaria posdoctoral interna del Consejo Nacional de Investigaciones Científicas y Técnicas [Conicet] y profesora de la Universidad de Buenos Aires. ORCID: 0000-0001-8571-6945.

Correo electrónico: florenciaduva87@gmail.com 


\title{
Los trabajos de mujeres y menores en los ferrocarriles de la Argentina a comienzos del siglo XX
}

\author{
Florencia D’Uva
}

\section{Introducción}

A comienzos de 1916, la comisión técnica encargada de asesorar a los jubilaciones y pensiones para el personal ferroviario llevó a cabo un censo de empleados y obreros del riel con el fin de recabar información para determinar el tiempo, la edad, el monto y las demás condiciones de los retiros. Entre los 36,344 trabajadores censados, quienes representaban aproximadamente un 30\% del personal total, se registraron 371 mujeres y 820 menores de 15 años, cifras que confirmaban la fuerte impronta masculina y adulta en el mundo laboral ferroviario, en el cual las mujeres y los menores constituían respectivamente alrededor del 1\% y 2\% del personal registrado. ${ }^{1}$ Pero, más allá de su baja representación numérica, ¿quiénes eran esas mujeres y menores? ¿Qué puestos ocupaban? ¿Cómo accedían a ellos? Estas son algunas de las preguntas que el presente artículo se propone responder con el fin de indagar la diversidad de experiencias obreras y las relaciones de trabajo existentes en los ferrocarriles de la Argentina a principios del siglo pasado.

Durante los últimos años, diversas investigaciones se encargaron de estudiar el mundo del trabajo ferroviario incorporando al análisis una perspectiva de género.

1. Alejandro E. Bunge, Ferrocarriles argentinos. Contribución al estudio del patrimonio nacional (Buenos Aires: Imprenta Mercantil, 1918) 317-325. Al comenzar 1916, se estimaba que el personal total de los ferrocarriles de la Argentina era de 117,000 empleados y obreros, por ende, los trabajadores censados representaban un 31\% del personal total de los ferrocarriles. Ministerio de Obras Públicas. Dirección General de Ferrocarriles, Estadística de los Ferrocarriles en Explotación, t. 24 (Buenos Aires: Talleres Gráficos del Ministerio de Obras Públicas, 1920) 335. Si bien la mayoría de las mujeres parece haberse ocupado en las oficinas administrativas de las compañías ferrocarrileras, generalmente como dactilógrafas, aquí el análisis se detiene en los denominados "obreros", dejando de lado a los empleados ocupados en el sector administrativo de los ferrocarriles. Sobre la feminización de la dactilografia, así como de otros empleos de escritorio, véase Graciela Queirolo, Mujeres en las oficinas. Trabajo, género y clase en el sector administrativo (Buenos Aires, 1910-1950) (Buenos Aires: Biblos, 2018). 
Por un lado, los estudios de Silvana Palermo sobre las huelgas de 1917 han examinado la participación de las mujeres en las protestas y destacaron la necesidad de considerar la centralidad de la familia en la experiencia de movilización y politización en este mundo laboral, así como el rol que ciertas concepciones de masculinidad - en especial aquellas ligadas al ideal del varón proveedor y al ejercicio de una paternidad responsable - jugaron en la estructuración de las demandas obreras. ${ }^{2}$ Otros trabajos examinaron las instancias de sociabilidad y solidaridad que tuvieron lugar entre los ferroviarios y sus organizaciones gremiales, con especial atención en los ideales de género y las nociones sobre la diferencia sexual que moldearon la construcción de sociabilidades y solidaridades de clase. ${ }^{3}$ Asimismo, algunas investigaciones indagaron en la configuración de las masculinidades ferrocarrileras con el objetivo de recuperar los mecanismos mediante los cuales los trabajadores y sus sindicatos imprimieron valores y sentidos con signo masculino a sus prácticas y experiencias. ${ }^{4}$

Si bien estas pesquisas han permitido comprender la centralidad del género en las experiencias laborales, sindicales y en las acciones colectivas que tuvieron lugar en el mundo laboral de los ferrocarriles, todavía es poco lo que se sabe sobre la participación de mujeres y menores en el trabajo ferroviario. ${ }^{5}$ Aunque algunas de

2. Silvana A. Palermo, "¿Trabajo masculino, protesta femenina? La participación de la mujer en la gran huelga ferroviaria de 1917”, Historias de luchas, resistencias y representaciones. Mujeres en la Argentina, siglos XIX y XX, comps. María Celia Bravo y otras (Tucumán: Editorial de la Universidad Nacional de Tucumán, 2007) 91-122; Silvana A. Palermo, "El derecho a mantener el hogar: las demandas obreras en la gran huelga ferroviaria desde una perspectiva de género. Argentina, 1917", Vivir con lo justo. Estudios de historia social del trabajo en perspectiva de género. Argentina, siglos XIX y XX, Andrea Andújar y otras (Rosario: Prohistoria, 2016) 81-101; Silvana A. Palermo, “En nombre del hogar proletario. Engendering the 1917 Great Railroad Strike in Argentina”, Hispanic American Historical Review 93.4 (2013): 585-620.

3. Florencia D’Uva y Silvana A. Palermo, "Vida sindical y sociabilidades masculinas: los trabajadores ferroviarios en la Argentina de principios del siglo XX", Archivos 7 (2015): 37-58; Florencia D’Uva, "Ayuda mutua, solidaridad gremial y género entre los trabajadores ferroviarios. Argentina, 1912-1917", Boletín del Instituto de Historia Argentina y Americana "Dr. Emilio Ravignani" 51 (2019): 87-122.

4. Florencia D’Uva, "Masculinidades obreras en los ferrocarriles: fuerza física, riesgos y responsabilidad profesional en la Argentina de principios del siglo XX”, Estudios del ISHIR 25 (2019): 1-22; Silvana A. Palermo, "Masculinidade, conflitos e solidariedades no mundo do trabalho ferroviário na Argentina (1912-1917)", Mundos do Trabalho 1.2 (2009): 94-123.

5. Respecto a la participación femenina en el trabajo ferroviario existen unos pocos estudios que examinaron la situación de las mujeres trabajadoras en distintos momentos del siglo XX. Entre ellos, Laura Badaloni, "Huelga Ferroviaria de 1917.Violencia, complot maximalista y mujeres incendiarias”, Imaginarios y prácticas de un orden burgués. Rosario, 1850-1930, t. 2, dir. Marta Bonaudo (Rosario: Prohistoria, 2010) 95-116; Mariela Canali, “¿Mujeres en el Ferrocarril?”, Historia Ferroviaria I, Jorge Tartarini y otros (Morón: Asociación de Amigos y Amigas del Instituto y Archivo Histórico Municipal de Morón, 2012) 99-107; Solange Godoy, "El conflicto de las camareras del ferrocarril Mitre: tensiones en el mundo del trabajo ferroviario en contextos de reestructuración y modernización (Argentina, 1962-1964)", Revista Notas Históricas y Geográficas 24 (2020): 168-202. 
las investigaciones mencionadas los descubrieron tomando parte activa en los momentos de lucha, participando de actividades y espacios gremiales, o como parte de la vida familiar de los trabajadores, aquí se busca examinar otro aspecto de su experiencia, como fue el de su inserción particular, aunque minoritaria, en el proceso de trabajo y el cotidiano laboral. Al poner el foco en las mujeres y menores, sus condiciones de trabajo y las características de las tareas que desarrollaban, este artículo busca destacar la multiplicidad de relaciones, arreglos y modalidades laborales existentes en los ferrocarriles y complejizar ciertas interpretaciones que han visto en estos un escenario de trabajo exclusivamente masculino y adulto.

Para lograr su objetivo, este escrito se vale principalmente de la Revista del Ferrocarril Central Argentino, publicación mensual de la compañía de capitales británicos, así como de reglamentos de diversas empresas, periódicos de los gremios ferroviarios, prensa partidaria y comercial. Algunas de estas publicaciones contaban con fotografias que permiten visibilizar a un conjunto de sujetos que pasaron desapercibidos en otras fuentes y registrar la materialidad de ciertos espacios de trabajo y de morada, a la vez que reconocer algunas de las tareas laborales llevadas adelante por mujeres, menores y grupos familiares. Mientras que la primera parte del artículo reconstruye los trabajos llevados a cabo por menores y mujeres en las estaciones de ferrocarril, el segundo apartado examina las variadas formas en que las mujeres participaron de la atención de los pasos a nivel como guardabarreras.

\section{El trabajo de menores y mujeres en las estaciones}

Las estaciones ferroviarias eran espacios que reunían a trabajadores con diversas profesiones, oficios y tareas. Junto con el jefe de estación, quien constituía la máxima autoridad, se desempeñaban auxiliares, dependientes, boleteros, cambistas, telegrafistas, peones, mensajeros y practicantes. Estos últimos ocupaban un lugar particular, diferente al del resto de los trabajadores de la estación.

Mensajeros y practicantes solían comenzar en estos puestos siendo muchachos jóvenes, menores de 16 años, ${ }^{6}$ los cuales en general cumplían un horario fijo en la estación y no se les pagaba salvo que tuvieran que hacer algún reemplazo como, por ejemplo, atender el telégrafo; de este modo era como se iniciaban en las tareas y en el aprendizaje del oficio. ${ }^{7}$ Según informó el diario La Época a mediados de 1916 en una nota sobre las condiciones de trabajo del personal de los ferrocarriles, en muchas estaciones de campaña el puesto de telegrafista se iniciaba con menores cuyos padres no tenían ningún inconveniente en que obtuvieran el aprendizaje

6. Julián García, "Siluetas ferroviarias. El jefe de...", Revista del Ferrocarril Central Argentino (Buenos Aires) mayo de 1915: 388.

7. María Luisa Fernández, coord., Las Flores, historias de la vida cotidiana (1856-1956), t. 2 (La Plata: Instituto Cultural de la Provincia de Buenos Aires y Municipalidad de Las Flores, 2006) 29; Raquel Tarullo y Alfonsina Iacullo, Ferroviarios. Nuestra historia (Junín: Universidad Nacional Noroeste de la Provincia de Buenos Aires, 2013) 97. 
sin recibir ninguna retribución. ${ }^{8}$ De hecho, es factible que los mismos padres o familiares empleados en las estaciones introdujeran a sus hijos en el servicio, como invita a pensar la Figura 1, publicada en la Revista del Ferrocarril Central Argentino, en la que, entre el personal de la estación Rafaela, se ve al mensajero de corta edad Alberto Colazo — sentado en el cordón del andén, a la izquierda de un practicante- y a un empleado de cargas del mismo apellido.

Si bien no deben perderse de vista los criterios estéticos y las convenciones, códigos y normas sociales de la época que moldearon las pautas del retrato fotográfico, las imágenes del personal de las estaciones condensan y traducen a un lenguaje visual la estructura jerárquica del trabajo en estos espacios. Los jefes generalmente aparecen sentados y ocupan el centro de la escena, rodeados del resto del personal a su cargo: ayudantes, encargados, auxiliares, telegrafistas. Los mensajeros y practicantes ocupan un lugar particular: están literalmente debajo del resto, por fuera del grupo principal de trabajadores, como una especie de agregado. Aun considerando que la pose de los grupos pudo haber obedecido a exigencias de quienes tomaban las instantáneas, ello no deja de decir algo sobre cómo esos contemporáneos pudieron haber concebido las jerarquías laborales. De hecho, si se tiene en cuenta el contexto en el que las fotografias fueron publicadas, en la revista mensual que la empresa distribuía entre su personal, es factible pensar que había un interés particular por reflejar las relaciones de autoridad y disciplina entre los trabajadores que ocupaban algún puesto de mando y aquellos subalternos. ${ }^{9}$

Según la crónica de La Época, el aprendizaje recibido resultaba "de bastante utilidad" para los muchachos, quienes, a la vez que adquirían práctica en la transmisión y la recepción de despachos telegráficos, mejoraban sus conocimientos de contabilidad, ya que los jefes se encontraban especialmente interesados en prepararlos para delegarles otras tareas. De hecho, en la publicación se aclaraba que la mayor parte de los jefes y altos empleados de tráfico se habían iniciado también como modestos aprendices. ${ }^{10}$ Seguramente muchos jovencitos —y sus padres - se entusiasmaban con la idea de aprender un oficio y aspiraban a hacer una carrera laboral en el ferrocarril, como se puede apreciar en el testimonio del mensajero

8. "Vida Obrera. El personal ferroviario. La situación en general de los empleados", La Época (Buenos Aires) 12 de junio de 1916: 6 .

9. Además, como señala Esmeralda Ballesteros Doncel para el caso español, no todos los puestos laborales ferroviarios resultaban "fotografiables" para las compañías, y las imágenes solían concentrarse en aquellas ocupaciones "expresivas de una nueva profesión distinguida". Véase Esmeralda Ballesteros Doncel, "Poder de representación pública y discriminación de género. La prensa gráfica como productor de estereotipos de la feminidad" (Ponencia, XII Congreso Español de Sociología, Universidad de Oviedo, 2016). En el caso del Ferrocarril Central Argentino, las páginas de la revista empresarial estaban plagadas de imágenes de personal superior — tales como jefes e ingenieros - con algún lugar reservado para guardas, inspectores y personal de estación, es decir, aquellos trabajadores que tenían cierta jerarquía en relación a otros, y los cuales mantenían un contacto más estrecho con el público viajero.

10. "Vida Obrera. El personal ferroviario. La situación en general de los empleados", La Época (Buenos Aires) 12 de junio de 1916: 6. 
Figura 1. Personal de la estación Rafaela del Ferrocarril Central Argentino

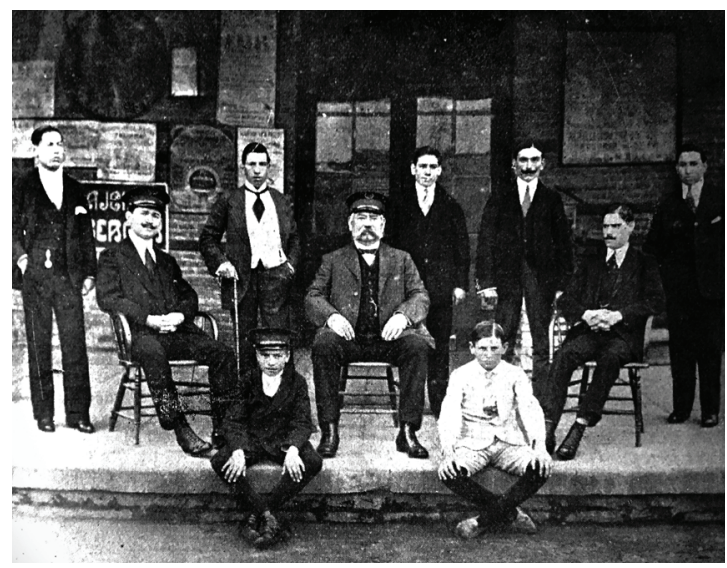

Figura 2. Personal de la estación Belgrano C. del Ferrocarril Central Argentino

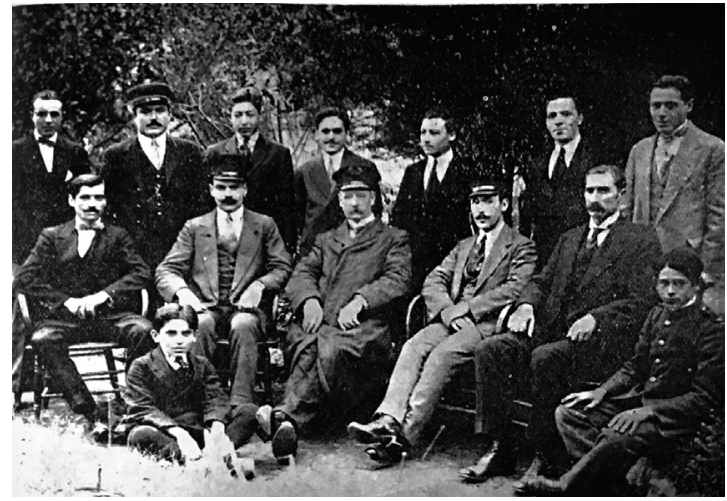

Figura 3. Personal de la estación Saira del Ferrocarril Central Argentino

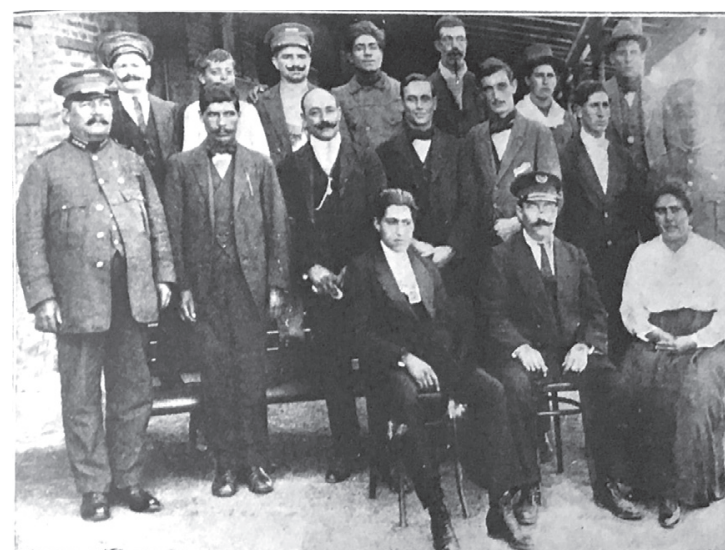

Fuente: Revista del Ferrocarril Central Argentino (Buenos Aires) junio de 1915: 465.

Fuente: Revista del Ferrocarril Central Argentino (Buenos Aires) agosto de 1915: 621 .
Fuente: Revista del Ferrocarril Central Argentino (Buenos Aires) abril de 1919: 61. 
Enrique Felini, de tan solo 12 años de edad, hijo de una viuda pobre y el mayor de cuatro hermanos, publicado en la Revista del Ferrocarril Central Argentino en octubre de 1913. Ante la pregunta del reportero de la compañía sobre cuáles eran sus aspiraciones en el ferrocarril, Enrique respondió que su propósito era ayudar a su mamá y a sus hermanitos y también "hacer carrera". ${ }^{11}$

En efecto, era cierto que muchas personas con cargos de autoridad, como era el caso de los jefes de estación, habían comenzado en estos puestos. Así lo deja ver el relato publicado en la revista empresarial de agosto de 1920 sobre la trayectoria de Marcelino Vázquez, de 31 años, quien ocupaba el cargo de jefe de estación en La Banda, Santiago del Estero. Marcelino había ingresado a la compañía a los 14 años como practicante y había trabajado en diversos puestos y estaciones hasta llegar a ser jefe. ${ }^{12}$ Otra trayectoria laboral ascendente fue la de Romeo Varela, quien, en septiembre de 1920, con 36 años, era el jefe de la importante estación San Martín. Según informaba en una entrevista publicada por la revista del ferrocarril británico,Varela había ingresado al servicio de la empresa con 15 años "en el modesto cargo de mensajero", dos años más tarde había sido nombrado dependiente, luego pasó a desempeñarse como jefe relevante y en 1908 comenzó su carrera como jefe titular de estación en distintos puntos de la línea. "Siempre ha sido mi vocación llegar al cargo que hoy desempeño", le aseguró al reportero Bautista Martín. ${ }^{13}$ Por supuesto, así como había casos de trayectorias laborales ascendentes, de las que dan cuenta las páginas de la revista de la empresa, también había otros derroteros posibles y no siempre quienes se iniciaban como aprendices lograban hacer una carrera en el ferrocarril.

Para ascender al puesto de telegrafista, mensajeros y practicantes debían aprobar un examen relacionado con las materias de transmisión, recepción, comunicación de los aparatos, conmutadores, pilas, caligrafia, ortografia y aritmética. ${ }^{14}$ Una vez en el puesto, bajo vigilancia del jefe o encargado de la oficina de telégrafo, y supervisados a su vez por el jefe de estación, los telegrafistas debían llevar a cabo la transmisión y recepción de despachos, telegramas y demás comunicaciones. De forma diaria tenían que remitir un informe al jefe de tráfico con todas las irregularidades producidas en el servicio y los telegramas afectados por dichas causas. ${ }^{15} \mathrm{Al}$ retirarse del servicio, el empleado debía hacerle notar a su reemplazante, en presencia del jefe, el estado en que se encontraban los instrumentos (aparatos Morse, campanillas, relojes, fechadores) y el entrante debía tomar nota en caso de encontrar algún

11. Testimonio recuperado de Laura Badaloni, "La familia ferroviaria a principios del siglo XX: bienestar y lealtades de hierro en el Ferrocarril Central Argentino", Trabajadores y empresarios en la Argentina del siglo XX: indagaciones desde la historia social, comps. Daniel Dicósimo y Silvia Simonassi (Rosario: Prohistoria, 2011) 151.

12. "Señor Marcelino Vazquez", Revista del Ferrocarril Central Argentino (Buenos Aires) agosto de 1920: 42.

13. "Nuestras entrevistas con el señor Romeo Varela", Revista del Ferrocarril Central Argentino (Buenos Aires) septiembre de 1920: 41.

14. Ferrocarril Central de Córdoba, Reglamento del Telégrafo para Dirección y uso exclusivo de los Empleados de la Empresa. A regir desde el $1^{\circ}$ de Febrero de 1915, 9.

15. Ferrocarril Central de Córdoba, Reglamento del Telégrafo 9-12. 
desperfecto. ${ }^{16}$ Sobre sus condiciones de trabajo, una crónica publicada a principios de 1916 en La Época informó que, a excepción de quienes se desempeñaban en las grandes estaciones de la metrópoli, las capitales de provincia o los centros urbanos del interior, los telegrafistas en general trabajaban de 10 a 12 horas, con un descanso de un día por mes, y que, además de atender el telégrafo, debían encargarse del servicio de cargas, pasajeros, administración, encomiendas y desenvolvimiento general. Además, quienes trabajaban en estaciones chicas debían levantarse por la noche para recibir a los trenes nocturnos. Los salarios mensuales oscilaban entre los 70 y los 100 pesos, dependiendo del tipo de estación y la categoría del trabajador, la cual estaba determinada por la antigüedad. ${ }^{17}$

Si bien los reglamentos de algunas empresas determinaban que para ingresar como telegrafista los aspirantes debían tener al menos 16 años, ${ }^{18}$ podían existir excepciones, como informó la revista semanal Caras y Caretas a fines de 1912, al dar cuenta del caso de Julio González, quien con tan solo 10 años de edad prestaba servicio como telegrafista en el ferrocarril Pacífico y lograba satisfacer las exigencias de la "disciplina ferrocarrilera". ${ }^{19}$ Sin embargo, a juzgar por los estatutos de la Confederación de Ferrocarrileros — gremio creado en 1902 para nuclear a señaleros, cambistas, guardas y peones-, la ocupación de menores podía despertar recelos por parte de los trabajadores organizados. Allí se especificaban como fines del gremio el evitar la participación de menores de edad en los servicios que implicaran algún peligro, así como impedir la admisión de los menores de 14 años en las empresas. ${ }^{20}$ Dichas propuestas coincidían con aquellas que algunos reformistas sociales comenzaban a formular en los primeros años del siglo XX, aunque, a diferencia de estos, que buscaban regular el trabajo de los menores con el fin de proteger y salvaguardar su moralidad y su salud, ${ }^{21}$ el móvil que guiaba a los obreros

16. Ferrocarril Midland de Buenos Aires, Reglamento Interno (Buenos Aires: Imprenta "Victoria" de Anderson \& Co., 1911) 53.

17. "Vida Obrera. El gremio de telegrafistas", La Época (Buenos Aires) 25 de enero de 1916: 6. Más de diez años antes, el médico y abogado Juan Bialet Massé también había llamado la atención sobre el trabajo excesivo del personal de muchas estaciones.Véase Juan Bialet Massé, Informe sobre el estado de las clases obreras en el interior de la República, t. 3 (Buenos Aires: Imprenta y Casa Editora de Adolfo Grau, 1904) 359.

18. Ferrocarril Central de Córdoba, Reglamento del Telégrafo 9. A partir del escalafón de telegrafistas sancionado a fines de 1921, la edad mínima para optar por el puesto de telegrafista fue estipulada en 18 años. Véase "Escalafón de telegrafistas", El Obrero Ferroviario (Buenos Aires) 1 de noviembre de 1921: 1.

19. "Precocidad", Caras y Caretas (Buenos Aires) 9 de noviembre de 1912.

20. Boletín del Departamento Nacional del Trabajo (Buenos Aires) marzo de 1908: 70. Más de una década después de la fundación de la Confederación, la cuestión seguía vigente y durante las huelgas ferroviarias de 1917 algunas de las demandas obreras apuntaron contra la contratación de menores. Palermo, "El derecho a mantener" 91.

21. En 1906, el diputado socialista Alfredo Palacios presentó su proyecto de ley de trabajo de mujeres y menores, el cual buscaba reducir la jornada laboral de estos e impedir el empleo de menores de 14 años de edad. En septiembre de 1907, tras algunas modificaciones, la ley fue aprobada y 
organizados estaba relacionado con la competencia que implicaban los salarios más bajos, cuando no nulos, que podrían cobrar los niños y jóvenes ocupados en las estaciones y como aprendices en los talleres y depósitos de locomotoras en los que se reparaba, mantenía y construía el material rodante. ${ }^{22}$

Las estaciones también fueron un espacio en el que se desempeñaron algunas mujeres ocupadas por las compañías ferrocarrileras como telegrafistas y dependientes. Aunque las evidencias resultan esquivas, parece ser que no se trató de un fenómeno generalizado, sino más bien de casos excepcionales. ${ }^{23}$ Una de esas trabajadoras fue Amalia P. de Quieto, quien en 1915 quedó registrada en la Revista del Ferrocarril Central Argentino como telegrafista de la estación Benjamín Gould (departamento de Unión, provincia de Córdoba), de la cual Carlos Quieto, probablemente su esposo, era el jefe. ${ }^{24}$ En 1919, Amalia fue retratada como telegrafista en la cercana estación Saira (localidad deVilla María, provincia de Córdoba) donde también Carlos era jefe. ${ }^{25}$ En la foto, tomada a comienzos de 1919 en Saira, se la puede ver posando junto con el resto del personal de la estación, así como con algunos trabajadores de tracción, prolijamente dispuestos en tres filas. Una primera hilera de trabajadores parados arriba de un banco se ubica detrás de otra fila de trabajadores que se encuentran de pie. Delante de todo, sentados, se encuentran el

estableció que el trabajo de los menores de 10 años no podría ser objeto de contrato, así como tampoco el de los mayores de esa edad que no hubieran completado la instrucción escolar obligatoria. Tampoco se podría ocupar a menores de 16 en trabajos nocturnos o trabajos capaces de dañar su salud, instrucción o moralidad. En la Capital Federal, el trabajo de los menores de 16 años fue limitado a ocho horas por día y 48 semanales. Véase Boletín del Departamento Nacional del Trabajo (Buenos Aires) julio de 1914: 9. A comienzos del siglo XX, la preocupación por la moralidad de mujeres y menores, así como por la capacidad reproductiva de las mujeres, no era exclusividad de los socialistas, sino que era compartida por intelectuales y reformistas sociales. Para más información, véase Marcela Nari, Políticas de maternidad y maternalismo político. Buenos Aires, 1890-1940 (Buenos Aires: Biblos, 2004).

22. El caso de los aprendices de los talleres y depósitos merece un tratamiento aparte. Si bien no es el objetivo de este artículo ocuparse de estos trabajadores, vale la pena aclarar que, a pesar de las diferencias existentes entre las distintas compañías, en general, los aprendices - muchachos de 15 años en adelante - recibían una paga por hora, aunque menor que la de los obreros calificados con formación de artesanos. Por ejemplo, según el informe de Bialet Massé, mientras que en los ferrocarriles de Corrientes y Entre Ríos los artesanos cobraban entre 20 y 70 centavos por hora, los aprendices percibían entre 6 y 20 centavos por hora trabajada.Véase Bialet Massé 130.

23. Desde mediados del siglo XIX, en distintos países, las mujeres se incorporaron al mundo del trabajo como telegrafistas, gran parte de las cuales fueron empleadas por compañías ferroviarias. A comienzos de 1920, de 78 mil telegrafistas ocupados en los ferrocarriles de Estados Unidos y Canadá, alrededor de 2,500 —es decir, un poco más del 3\% - eran mujeres. Véase Charles H. Garland, "Women as Telegraphists", The Economic Journal (Oxford) junio de 1901: 251-261; Thomas C. Jepsen, My Sisters Telegraphic. Women in the Telgraph Office, 1846-1950 (Ohio: Ohio University Press, 2000) 54.

24. Revista del Ferrocarril Central Argentino (Buenos Aires) mayo de 1915: 381; Revista del Ferrocarril Central Argentino (Buenos Aires) junio de 1915: 458.

25. Revista del Ferrocarril Central Argentino (Buenos Aires) abril de 1919: 61. 
auxiliar de la estación, el jefe y Amalia, que desde el borde parece estar casi excluida del grupo, aunque ocupe un lugar al lado de la máxima autoridad de la estación.

La Revista del Ferrocarril Central Argentino también registró como telegrafista de la empresa a la señorita Rosa Fischer, quien se desempeñaba en la estación cordobesa Coronel Baigorria, de la cual su hermano, Ramón E. Fischer, era jefe. Sobre Rosa, la revista informó que formaba parte del personal desde diciembre de 1914, siete meses antes de realizarse la nota, y que "por su despejada inteligencia promete ser una hábil telegrafista, encontrándose ya en grado de entender muchos de los detalles del servicio de una estación". ${ }^{26}$ Resulta interesante advertir que tanto Rosa como Amalia tenían una relación de parentesco con quien se desempeñaba como jefe de estación, lo que sugiere que era necesario tener algún contacto o recomendación para acceder a este oficio siendo mujer. Lo mismo puede decirse de las mujeres que se desempeñaban como dependientas en las estaciones, ocupándose, entre otras tareas, de atender consultas de los pasajeros o de la limpieza y orden de andenes y zonas de espera. Si bien, nuevamente, es poca la información disponible sobre estas trabajadoras, la Revista del Ferrocarril Central Argentino ofrece dos casos, ambos correspondientes al año 1920: el de la señorita Carmen Citta, dependienta en la estación San Severo, provincia de Córdoba, donde su padre se desempeñaba como jefe de estación, y el de Rosario Mistretta, dependienta en la estación Sancti Spiritu, al sur de la provincia de Santa Fe, de la que su hermano Antonio era el jefe. ${ }^{27}$

Quizás las redes de parentesco que existían entre estas mujeres y los jefes de estación tuvieran que ver con ciertas características de los trabajos que las primeras desempeñaban, signados por jornadas laborales largas — sujetas a prolongarse a causa de demoras o imprevistos en el servicio - y desarrolladas en espacios públicos, como eran las estaciones ferroviarias, a las que concurrían y en las que transitaban personas de distintas clases sociales, y cerca de las cuales podía haber prostíbulos y tabernas. ${ }^{28}$ De este modo, el entorno laboral de las estaciones podía ser considerado como peligroso y una amenaza para la moralidad de las mujeres "solas" que no contaran con la tutela de un varón. Asimismo, en los pueblos y las localidades alejados de las zonas urbanas, era frecuente que las estaciones fueran el lugar de residencia de los jefes o que sus casas estuvieran ubicadas de manera contigua a la estación. En el caso de las telegrafistas, lo cierto es que las hijas, esposas o hermanas de los jefes que compartían el espacio de morada con estos podían aprovechar su cercanía al espacio laboral de la estación para aprender un oficio

26. "Nuestros empleados y sus familias", Revista del Ferrocarril Central Argentino (Buenos Aires) julio de 1915: 544.

27. "Fotografias varias", Revista del Ferrocarril Central Argentino (Buenos Aires) agosto de 1920: 53 y 55.

28. Sobre los vínculos entre el trazado del ferrocarril y la prostitución en la Argentina, véase María Elba Argeri, “'La peor plaga que pudo haber traído la locomotora'. Prostitución y control estatal en un Territorio Nacional Norpatagónico: Río Negro 1880-1920", Anuario de Estudios Americanos 56.1 (1999): 217-235; María Alejandra Saus, "Entre el ferrocarril y los prostíbulos: derrotero de una frágil urbanización”, Registros 10 (2013): 112-127. 
prestigioso y socialmente respetable en la Argentina de comienzos del siglo XX. Resulta probable que los propios jefes entrenaran a estas mujeres en el manejo del telégrafo, preparándolas con las habilidades necesarias para ejercer el oficio, ya que, para llegar a la jefatura de estación, uno de los requisitos era ser un hábil telegrafista. ${ }^{29}$ Por otra parte, en las estaciones donde no había demasiado tráfico, quizás las mujeres telegrafistas podían conciliar sus obligaciones laborales con sus responsabilidades familiares y tareas de cuidado, lo que hacía más atractivo un empleo que seguramente ya de por sí resultaba más deseable que el trabajo fabril o el servicio doméstico. ${ }^{30}$

En suma, las situaciones examinadas en este apartado ponen de relieve la diversidad del mundo laboral en las estaciones ferroviarias, en las que convivían trabajadores de oficio con trabajadores sin calificación; hombres con largos años de experiencia, que realizaban un trabajo remunerado, con niños o muchachos que recién se iniciaban en puestos de aprendizaje y no cobraban un salario; varones en puestos de autoridad con mujeres que ocupaban trabajos calificados y no calificados. También queda en evidencia la importancia de las relaciones familiares y las redes de parentesco en la incorporación al mercado formal del trabajo ferroviario, ya que muchos trabajadores recomendaban o promovían el contacto entre las compañías y sus hijos, hijas, hermanas o esposas, lo que fomentaba cierta endogamia ferroviaria.

\section{Mujeres y familias en las barreras}

Los guardabarreras o guardavías también formaban parte del personal de estaciones, aunque su lugar de trabajo no era este, sino la vera de las vías, en donde cumplían múltiples y diversas tareas. Entre otras actividades, se encargaban del control de los pasos a nivel y de cerrar las barreras cuando pasaban los trenes, al pararse frente a estas con una bandera desplegada durante el día, o con el farol de mano durante la noche, a fin de poder ser vistos por el maquinista. También eran los encargados de anunciar los trenes, en general con una campanilla, para que el guardavía de la estación o garita más próxima estuviera atento a bajar la barrera a su cargo. Debían encender y apagar las luces de las barreras, hacer señales con petardos en caso de neblina y hacer las señales de peligro correspondientes en caso de que la vía se encontrara interrumpida u obstruida. Asimismo, debían impedir el tránsito por la vía,

29. Respecto a los mecanismos por medio de los cuales las mujeres pudieron haber aprendido el oficio de telegrafistas, no fue posible hallar evidencias sobre mujeres menores mensajeras o practicantes, ni tampoco parecen haber existido escuelas o cursos de telegrafia promovidos $\mathrm{u}$ organizados por las autoridades de las empresas ferroviarias, como sucedió en otras latitudes.

30. Más allá del prestigio del que gozaba la telegrafia, es probable que las mujeres que ejercían el oficio en los ferrocarriles ganaran menos que sus pares varones, quienes igualmente cobraban salarios más bajos que aquellos telegrafistas ocupados en la Dirección General de Correos y Telégrafos. Véase "Vida Obrera. El personal ferroviario. La situación en general de los empleados", La Época (Buenos Aires) 12 de junio de 1916: 6. 
para lo cual podían recurrir a la fuerza pública en caso de que algún transeúnte no quisiera librar el paso a nivel o insistiera en caminar por allí; de igual modo procederían con los conductores de vehículos que causaran averías en las barreras, a fin de poder cobrarles el daño ocasionado. También era su obligación conservar limpios los pasos a nivel, las barreras y los instrumentos de trabajo, así como sus casillas, en las cuales estaba prohibido alojar a personas que no fueran de su familia. ${ }^{31}$

Durante la noche, las barreras debían permanecer cerradas; solo podían ser abiertas para dar paso a peatones y vehículos, y quedarían levantadas donde los guardavías no permanecieran en servicio nocturno. En ese caso, al concluir la jornada, los guardas debían llevar los faroles a la estación a la que pertenecieran para volver a recogerlos al regresar a su puesto. Si notaran algún desperfecto en el funcionamiento de las barreras, debían avisar al jefe de estación o capataz de cuadrilla más próximo y pasar el parte al inspector de guardavía. También debían cuidar que los postes e hilos telegráficos se encontraran despejados de cualquier elemento que pudiera causar interferencias en las comunicaciones y debían impedir la entrada de animales en la vía, así como retirar a aquellos que hubieran sido atropellados por un tren. En caso de accidentes, darían aviso enseguida al jefe inmediato y conseguirían testigos que pudieran declarar sobre cómo se había producido el hecho. Entre sus elementos de trabajo se encontraban un juego de banderas, un farol, petardos, un pito, el horario de los trenes, así como una pala y escoba para realizar la limpieza correspondiente. ${ }^{32}$

Algunos guardavías vivían con sus familias en las casillas que las empresas les facilitaban y, en estos casos, también las mujeres, los hijos y otros familiares podían encargarse de algunas de las tareas que implicaba el puesto de atender la barrera. Al respecto, en marzo de 1904, el periódico socialista La Vanguardia apuntó contra el bajo salario de estos trabajadores, al denunciar que por 30 pesos las empresas explotaban a dos personas, "o sea al guardabarreras y su mujer o su hijo, que se alternan durante las 21 horas de trabajo que hacen". ${ }^{33}$ Ese mismo año, un mes antes, un pasajero del Central Argentino había informado que los guardabarreras de esa empresa, al recibir un pago mensual de 30 pesos, el cual no alcanzaba para cubrir las necesidades básicas, buscaban otros trabajos y dejaban la barrera al cuidado de sus mujeres, "las que ayudadas por algún muchacho propio o ajeno cumplen como pueden". ${ }^{34}$ De hecho, algunas evidencias sugieren que las empresas preferían y

31. Ferrocarril del Sud, Reglamento para el uso y gobierno de los empleados de la empresa solamente. En vigencia desde el 19 de noviembre de 1910 (1910) 127-130; Ferrocarril Midland de Buenos Aires 77-79; Ferrocarril Central de Córdoba, Reglamento general para el uso y gobierno de los empleados de la empresa solamente (Buenos Aires: Imprenta Cagnasso y Milone, 1915) 111-112; Ferrocarril Central de Córdoba, Reglamento del Telégrafo 36.

32. Ferrocarril del Sud 127-130; Ferrocarril Midland de Buenos Aires 77-79; Ferrocarril Central de Córdoba, Reglamento general 111-112; Ferrocarril Central de Córdoba, Reglamento del Telégrafo 36.

33. "Mucanga burguesa", La Vanguardia (Buenos Aires) 5 de marzo de 1904: 2. Agradezco a Lucas Poy por haber compartido conmigo esta información.

34. Citado en Badaloni, "Huelga ferroviaria" 103. 
buscaban explícitamente matrimonios para cubrir los puestos de guardabarreras. En este sentido, resulta revelador el caso del guardabarrera de apellido Melli y su esposa Elvira María Corleto, quienes en 1935 encontraron una vacante publicada en el boletín del sindicato Unión Ferroviaria, en la que se pedía un matrimonio para atender la barrera de Gowland, ubicada a siete kilómetros de Mercedes, ciudad de la provincia de Buenos Aires. Según recordó años más tarde la hija de la pareja, su padre atendía la barrera durante la noche, mientras que Elvira lo hacía durante 12 horas del día, alternando dicha labor con las tareas domésticas: "ella estaba en casa, iba, lavaba la ropa, hacía todas sus cosas mientras atendía (...) todo al mismo tiempo: estaba en su casa, escuchaba la campanilla [que anunciaba el paso del tren] y atendía la barrera". 35

Sobre la cotidianeidad laboral de estos trabajadores, una crónica ilustrada que se publicó en la revista semanal Caras y Caretas en agosto de 1917 sobre la rutina de los guardavías del barrio porteño de Caballito, Ferrocarril Oeste, contó que en el paso a nivel de la calle Cucha Cucha el guarda era un joven padre de familia que pasaba los días acompañado casi siempre de su hijita en la boca del "huraco o caverna" que se había construido junto a la cadena de la barrera. Informó que, como el trabajo era tan excesivo en aquellos pasos, por donde transitaban más de cien trenes diarios, el guarda había tenido que acondicionar refugios para protegerse de la intemperie, y mantener a su mujer y a su suegra trabajando, "en constante vigilancia", desde las cinco de la mañana hasta las doce de la noche. ${ }^{36}$ Como puede interpretarse a partir de la nota, debido a la intensa jornada de trabajo, toda la familia trabajaba en el puesto laboral del varón y no siempre las empresas brindaban una casilla en la cual pudieran guarecerse de la intemperie; en esos casos, el guarda podía construirse una. ${ }^{37}$ Respecto al criollo que era guarda en la calle Caballito, se informó que era un excambista que se había dislocado un pie y que criaba perros en la casilla en donde lo acompañaba su "pobre mujer". Sobre el guardavía de la calle Rojas, el

35. Canali, “¿Mujeres en el Ferrocarril?” 102. La contratación de matrimonios para ocupar un mismo puesto laboral también se daba en el servicio doméstico de algunas empresas petroleras y, desde mediados de la década de los treinta, en la Unión Telefónica Río de la Plata, la que comenzó a promoverse la instalación de matrimonios para atender las oficinas en diversos lugares del interior del país. Dora Barrancos, "La puñalada de Amelia (o cómo se extinguió la discriminación de las mujeres casadas del servicio telefónico en la Argentina)", Trabajos y Comunicaciones 8.34 (2008): 124; Mirta Zaida Lobato, Historia de las trabajadoras en la Argentina (1869-1960) (Buenos Aires: Edhasa, 2007) 56.

36. "Los guardavías", Caras y Caretas (Buenos Aires) 4 de agosto de 1917.

37. Sobre las comodidades de estos espacios, en septiembre de 1912, algunos guardavías de la sección La Plata del Ferrocarril Sud se quejaban de las nuevas garitas que la empresa daba en lugar de las antiguas casillas. Denunciaban que estas eran de apenas 80 centímetros cuadrados y que, al no tener ventanas en los laterales, era necesario estar constantemente afuera para ver si venían trenes. Véase "Sección La Plata. La avaricia más cruel que la inquisición", El Obrero Ferroviario (Buenos Aires) septiembre de 1912: 4. 
cronista contó que era un garibaldino "madurito" y enamorado que, junto con una chaqueña, se encargaba de llevar adelante las tareas del puesto. ${ }^{38}$

En los tres casos de los que dio cuenta la revista, los guardas se encontraban acompañados por mujeres, quienes podían encargarse de algunas de las obligaciones que implicaba la barrera, situación de la que estaban al tanto las autoridades de las compañías ferrocarrileras. De hecho, un año después de publicada la crónica en Caras y Caretas, un decreto aclaratorio del reglamento de trabajo sancionado en 1917 especificaba que los guardabarreras a quienes las empresas facilitaran casillas podrían prestar servicio hasta por doce horas, siempre que el paso a nivel estuviese atendido continuamente "por dos personas de la misma familia". 39

Las fotografias publicadas junto a la crónica, seguramente dirigidas por el autor de las instantáneas, quien buscó contar y representar la cotidianeidad del trabajo de los guardavías a través de algunas puestas en escena, permiten apreciar cómo las labores de los pasos a nivel eran compartidas por todos los miembros de la familia. Abrir y cerrar la barrera, pasar la escoba, preparar la comida y realizar tareas de orden y limpieza eran parte del trabajo que realizaban los guardas, sus hijos e hijas, esposas o compañeras, e inclusive suegras. Las imágenes ponen estas labores en primer plano y evidencian la variedad de tareas implicadas en el puesto de guardabarrera, a la vez que permiten imaginar la intimidad de la vida en una casilla al costado de las vías. También hacen posible pensar en los vínculos existentes entre el trabajo en los pasos —en donde se situaban las casillas que generalmente hacían las veces de vivienda obrera - y los trabajos de cuidado y reproductivos de las mujeres, quienes, a la par que cumplían funciones como guardabarreras, atendían a su familia y sus obligaciones domésticas: cuidaban a los hijos, preparaban la comida, limpiaban o remendaban ropa.

Además de que en algunos pasos las familias se repartían el trabajo, aunque el puesto de guardavía era formalmente ocupado por un varón - generalmente el padre de familia-, también podía suceder que la barrera estuviera a cargo de una mujer. Este fue el caso de la señora de Liendo, viuda de un exmaquinista del Ferrocarril Central Argentino fallecido tras 17 años de servicio continuo. Hacia fines de 1916, la mujer era la guardabarrera de un paso a nivel en la estación Los Cardales, en la localidad homónima de la provincia de Buenos Aires, y junto con su hija de 17 años, la señorita María Liendo, trabajaba en la casilla al tiempo que se ayudaba a vivir con la crianza de aves, la venta de huevos caseros y algunos porcinos que ellas mismas cuidaban. ${ }^{40}$ En algunos casos, ante el fallecimiento de un trabajador, sobre todo cuando este ocurría como resultado de un accidente en servicio, las empresas ofrecían a las viudas o deudos alguna compensación no monetaria, como una colocación. No es posible saber si este fue el caso de las Liendo, pero sí fue lo

38. "Los guardavías", Caras y Caretas (Buenos Aires) 4 de agosto de 1917.

39. "Reglamentación del trabajo. Decretos y aclaraciones", El Obrero Ferroviario (Buenos Aires) septiembre de 1918: 4.

40. “Sta. María M. Liendo", Revista del Ferrocarril Central Argentino (Buenos Aires) octubre de 1916: 785. 

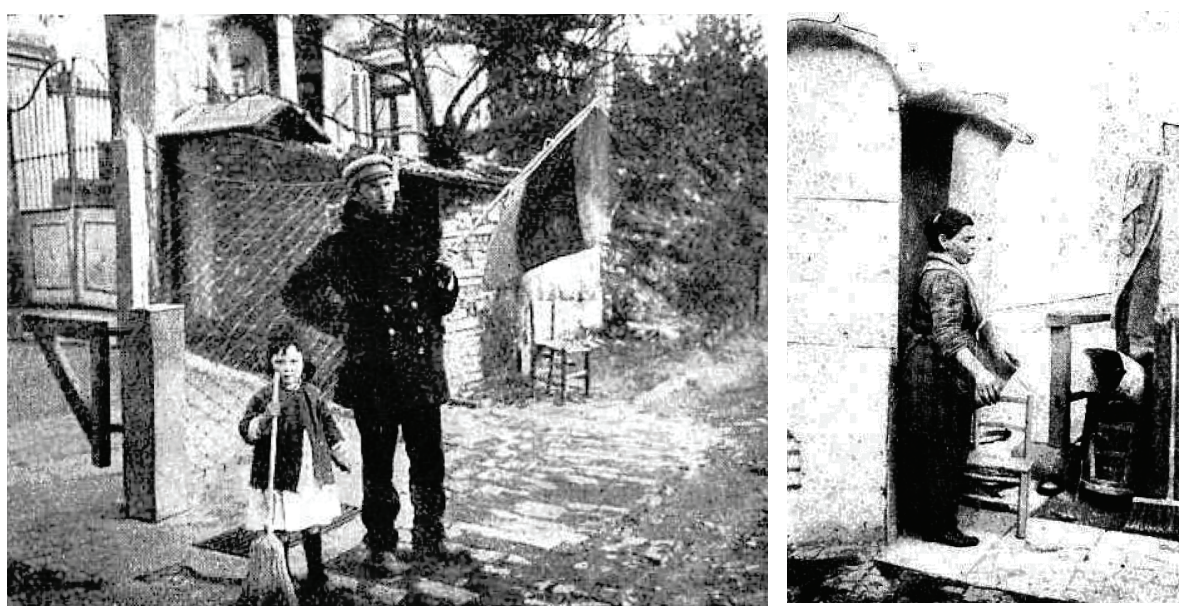

Fuente: Caras y Caretas (Buenos Aires) 4 de agosto de 1917.

Figura 6. Chalet del guardavía

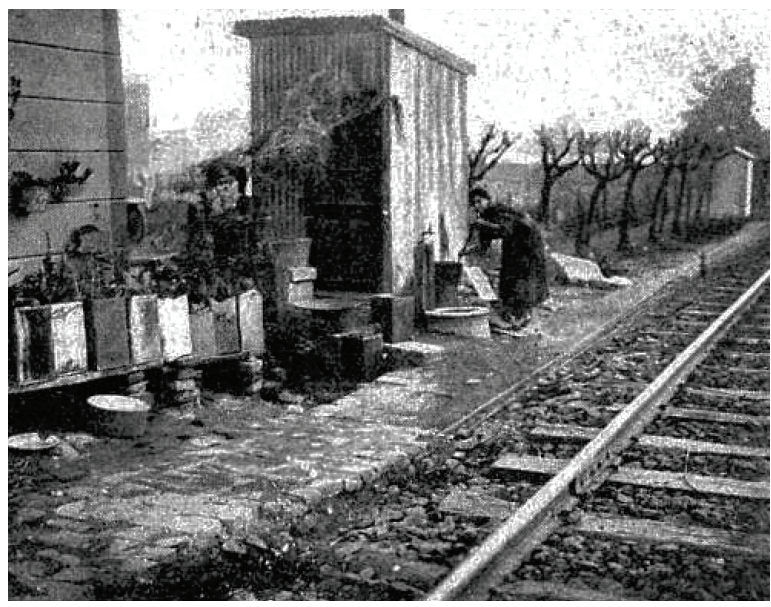

Figura 7. Guardavía cerrando las barreras

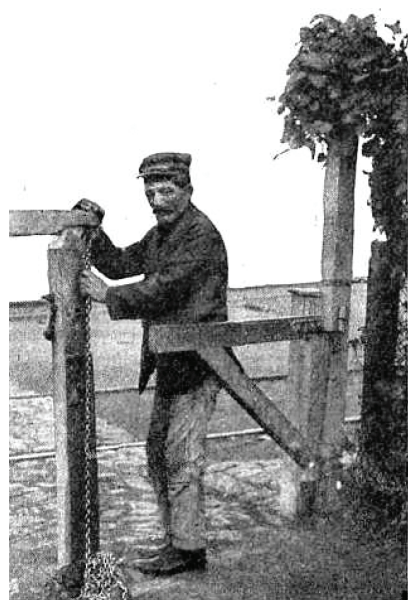

Fuente: Caras y Caretas (Buenos Aires) 4 de agosto de 1917.

que sucedió con Francisca Miranda de Rojas, quien, en 1924, con 19 años de edad, ingresó a trabajar como guardabarreras en el Ferrocarril Andino, luego de que su hermano, quien era el sostén de la familia, falleciera. Según el testimonio que brindó Francisca varias décadas después, "antes se daba vacante, no se daba sueldo como hacen ahora. Entonces buscaron una vacante, pero mamá tenía más de 80 años, 
entonces me buscaron a mí, me pertenecía a mí porque él me tenía a cargo". ${ }^{41} \mathrm{Si}$ bien Francisca se había postulado para ser telegrafista, aceptó el puesto de guardabarrera porque le prometieron que allí ganaría más y no pagaría casi nada. El trabajo comenzaba a las seis de la mañana y concluía a las diez de la noche, y exigía bastante tiempo y atención, pues los trenes, casi todos de carga, pasaban con bastante frecuencia: "a veces cuando eran muy seguidos se me cansaban los brazos. Más que todo me dolían las manos" recordaría años más tarde. ${ }^{42}$ Su testimonio impugna la concepción que algunas empresas tenían del trabajo de las mujeres guardabarreras. A mediados de 1926, por ejemplo, el Ferrocarril Pacífico aseguró que las tareas que desempeñaban esas empleadas, las cuales se realizaban en las inmediaciones del propio domicilio y generalmente durante las horas del día, no eran contiguas ni exigían esfuerzo corporal. ${ }^{43}$

Como sucede con otras mujeres que desempeñaban tareas en el ferrocarril, las evidencias sobre las guardabarreras resultan escasas y fragmentarias, lo que en este caso puntual se relaciona directamente con el hecho de que las estadísticas de las compañías y dependencias de gobierno solo registraron a aquellas que mantenían una relación laboral formal con las empresas. ${ }^{44}$ Como se ha visto aquí, lo cierto es que muchas mujeres realizaban trabajos en la casilla, que no pocas veces funcionaba al mismo tiempo como vivienda, aunque el puesto fuera de su marido, padre o yerno y ellas no mantuvieran una relación contractual con la compañía. En el caso de que fueran empleadas por la empresa, era factible —al igual que sucedía con otros puestos desempeñados por mujeres - que fueran familiares de trabajadores, muchas de las cuales continuaron desempeñando el puesto de sus maridos luego de que estos fallecieran. Así lo deja entrever el relato sobre Antonia V.Vallejos, guardabarrera de la calle Sucre, en la ciudad de Buenos Aires, quien, en algún momento de principios del siglo XX, reemplazó en el puesto a su esposo, el cual había estado

41. Canali, “¿Mujeres en el ferrocarril?” 100. En el caso español era común que las mujeres ocuparan el puesto de "guardesas". Como han demostrado distintos estudios, en muchos casos se trataba de las viudas o los huérfanos de trabajadores fallecidos en servicio, a quienes las empresas otorgaban el puesto de guardabarrera como forma de "reparación moral", previa renuncia a la indemnización por la muerte del familiar. Esmeralda Ballesteros Doncel, "La construcción del empleo ferroviario como una profesión masculina, 1857-1962", ¿Privilegios o eficiencia? Mujeres y hombres en los mercados de trabajo, eds. Carmen Sarasúa y Lina Gálvez (SanVicente de Raspeig: Universidad de Alicante, 2003) 335-354; Francisco de los Cobos Arteaga, "Redescubrir los trabajos ocultos. Las empresas ferroviarias y la mano de obra femenina (1850-1900)", Revista Transportes, Servicios y Telecomunicaciones 33 (2017): 12-32.

42. Canali, “¿Mujeres en el ferrocarril?” 101.

43. "Las mujeres guardabarreras y la ley 11317”, La Fraternidad (Buenos Aires) 5 de julio de 1926: 32.

44. En el Archivo de Ferrocarriles Argentinos, en donde se conservan las fichas y legajos del personal ferroviario, solo fue posible encontrar dos fichas pertenecientes a mujeres guardabarreras. Se trata de María Esther G. de Garrido, de nacionalidad argentina, quien, en 1926, con 24 años, ingresó al servicio, donde se desempeñó en distintos cruces hasta 1946, y de Virginia Sánchez de Torres, también argentina, quien en 1926 entró a trabajar como guardabarrera, con 43 años, hasta 1942, cuando se jubiló por "invalidez provisional". Archivo General del Ferrocarril (AGF), Buenos Aires, Recursos Humanos Ferroviarios, matrícula 28350 y 28400. 
en servicio durante más de veinte años y fallecido en un accidente de trabajo. En el marco de la huelga producida en el verano de 1904 entre los trabajadores del Ferrocarril Central Argentino, en ese entonces recientemente fusionado con el Ferrocarril Buenos Aires al Rosario, Antonia participó en una asamblea obrera en la que denunció que la empresa le estaba reclamando el puesto para dárselo a otro obrero, lo que invita a pensar en la inestabilidad y precariedad laboral de las mujeres que se desempeñaban en estos trabajos. ${ }^{45}$

Sobre las características y condiciones del trabajo de los guardabarreras, la citada crónica de Caras y Caretas afirmó que los guardavías eran casi siempre "viejos servidores inutilizados en el trabajo" que percibían exiguos jornales y a quienes no se les acordaba más beneficio que algunos pocos elementos de trabajo y una casilla "que se asemeja mucho a un tonel". ${ }^{46}$ En efecto, no eran pocos los trabajadores que luego de sufrir algún accidente o enfermedad que los dejaba inhabilitados para continuar desempeñándose en su puesto eran transferidos a un paso a nivel donde se les asignaba la tarea de atender una barrera, la cual no solo se presuponía que no demandaba grandes esfuerzos físicos, sino que, además, se trataba de una actividad que podía ser llevada a cabo con la colaboración de otros miembros de la familia. ${ }^{47}$ Respecto a los salarios de los guardabarreras, y a pesar de las diferencias que podían existir entre las diferentes empresas, lo cierto es que estos estaban entre los más bajos del personal ferrocarrilero, y eran similares a los que percibían los peones de vía y obras encargados del tendido y mantenimiento de las vías e instalaciones ferroviarias. Durante los primeros años del siglo XX, los guardavías cobraban salarios exiguos de entre 30 y 45 pesos mensuales por llevar a cabo una serie de tareas de las que generalmente, como se ha visto, se ocupaba todo un grupo familiar. ${ }^{48} \mathrm{~A}$ partir del reglamento de trabajo sancionado en 1917 como resultado de las huelgas que tuvieron lugar en la primavera de ese año, se estipularon algunos aumentos de

45. La Prensa (Buenos Aires) 1 de marzo de 1904: 2. Agradezco a Lucas Poy por haber compartido esta información conmigo.

46. "Los guardavías", Caras y Caretas (Buenos Aires) 4 de agosto de 1917.

47. Si bien el caso es de los años 50, en sus memorias ferroviarias, Juan Carlos Cena cita el testimonio de "La Betty", cuyo padre, tras un accidente en el que había perdido una pierna, fue ocupado en una casilla como guardabarrera. Betty recordaba que todos los días lo acompañaba a la casilla en la que frecuentemente ella o su hermano hacían de guardabarrera. Entre tren y tren, Betty hacía los deberes de la escuela, regaba las plantas "del jardincito" y tomaba mate con su padre.Véase Juan Carlos Cena, El guardapalabras: memorias de un ferroviario (Buenos Aires: La Rosa Blindada, 1998) 605.

48. Boletín del Departamento Nacional del Trabajo (Buenos Aires) enero de 1916: 133; “La organización y las luchas de los obreros ferroviarios", Periódico de la Confederación General del Trabajo (CGT) (Buenos Aires) octubre de 1934:3. Por su parte, los peones de vía y obras cobraban un salario de 1.25 pesos por día trabajado; mientras que un maquinista percibía un salario mensual promedio de 210 pesos; un foguista, 110 pesos; un guarda tren podía ganar alrededor de 90 pesos mensuales, y un trabajador calificado de los talleres 120 pesos por mes o más. Bialet Massé 349-351; "Escala de sueldos actuales", La Fraternidad (Buenos Aires) 1 de diciembre de 1911: 5; "C. General de Ferrocarriles de la P. de Buenos Aires", El Obrero Ferroviario (Buenos Aires) febrero de 1913: 3. 
sueldos, los cuales hacia mediados de la década de los veinte eran de alrededor de

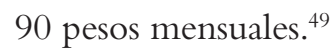

El relato sobre la viuda de Liendo y su hija, quienes trabajaban en una casilla del Ferrocarril Central Argentino, evidencia que los guardavías podían complementar sus ingresos con la tenencia de algunos animales domésticos destinados al uso y consumo propios. Esto estaba permitido por la mayoría de las compañías, era válido para todos los empleados que ocuparan propiedades de la empresa, como era el caso de guardabarreras, señaleros, jefes de estaciones, entre otros, y podía ser una manera de compensar los bajos salarios de algunos trabajadores. ${ }^{50}$ Inclusive, en su edición de agosto de 1920, la Revista del Ferrocarril Central Argentino recomendaba a sus empleados incursionar en la cría de aves, abejas y conejos, y afirmaba que la avicultura era un complemento indispensable de todos los hogares que quisieran tener la seguridad de "huevos frescos" y "carne sabrosa". 51

\section{Conclusiones}

Al reconstruir los trabajos desempeñados por mujeres, menores y grupos familiares, este artículo permitió poner en evidencia la diversidad y multiplicidad de experiencias que tuvieron lugar en el mundo laboral ferroviario en la Argentina de comienzos del siglo XX. Los ferrocarriles empleaban a una enorme cantidad de personal, de las más variadas especialidades, oficios y categorías, y con tareas que implicaban diversas exigencias, responsabilidades, saberes, calificaciones y esfuerzos físicos. Las diferencias de calificación, etarias y de género existentes entre los trabajadores del riel definieron jerarquías y segmentaciones internas, así como estatus laborales y sociales diferenciales que conllevaron distintos arreglos y relaciones de trabajo que no siempre estuvieron mediados por dinero, como sucedió especialmente con algunos menores y mujeres.

En particular, fue posible develar que las empresas necesitaron y se sirvieron del trabajo no pago ni reconocido de los familiares de sus trabajadores, al desplegar diversas modalidades laborales que incluyeron el trabajo de menores que no percibían un salario, y cuya compensación por su labor era el aprendizaje de un oficio, así como empleos que implicaron el trabajo de todo un núcleo familiar a cambio de un solo salario y vivienda, entre otros. Al revisar oficios, labores y espacios de trabajo, se ha visto que las mujeres no solamente se ocuparon de las tareas de reproducción esenciales para las vidas de los trabajadores, sino que

49. AGF, Buenos Aires, Recursos Humanos Ferroviarios, matrícula 28350 y 28400.

50. Ferrocarril Central Argentino, Apéndice del Reglamento General e Itinerario de Servicio. Departamento de Tráfico (Buenos Aires, 1922). La siembra y la cría de algunos animales podía significar un ingreso extra para algunos trabajadores. Así, por ejemplo, en 1915, un foguista de la Compañía General rebajado a limpiador decidió sembrar papas y vender la cosecha entre sus compañeros para paliar la mala situación económica.Véase "En la Compañía General”, La Fraternidad (Buenos Aires) 15 de abril de 1915:2.

51. Revista del Ferrocarril Central Argentino (Buenos Aires) agosto de 1920: 54. 
también llevaron a cabo labores específicas y necesarias para que el engranaje ferroviario funcionara. A veces fueron contratadas por las empresas y realizaron un trabajo remunerado y reconocido como tal, como fue el caso de las telegrafistas, las dependientas de estación y algunas guardabarreras. En otras ocasiones, como parte de un marco familiar, sostuvieron trabajos o tareas implicadas en los puestos laborales de sus padres, esposos, yernos o hijos, como sucedió con algunas mujeres que acompañaron activamente, trabajando a la par, a los guardabarreras en sus labores.

Al situar la mirada en el trabajo — a veces no reconocido ni remunerado- de las mujeres y los menores, este artículo complejiza la manera de pensar y concebir el trabajo ferroviario y contribuye a recuperar la multiplicidad de relaciones, prácticas y arreglos laborales que existían en los ferrocarriles en la Argentina de principios del siglo pasado y que exceden su conceptualización como trabajo formal, asalariado y masculino. Para que estos funcionaran no alcanzó con el trabajo de varones adultos, sino que mujeres, menores, jóvenes aprendices, esposas, hijas, hermanas y suegras de los trabajadores, insertas en relaciones asalariadas o no, realizando tareas que no siempre eran reconocidas como trabajo, contribuyeron a poner en marcha y sostener el servicio. A partir de ello, es posible repensar ciertas interpretaciones, significados y características atribuidas al trabajo en general, y comprender las variadas modalidades y formas de trabajo existentes en la Argentina de comienzos del siglo XX.

\section{Fuentes}

\section{Manuscritas}

Archivo General del Ferrocarril, Buenos Aires (AGF)

Recursos Humanos Ferroviarios

\section{Impresas}

Bialet Massé, Juan. Informe sobre el estado de las clases obreras en el interior de la República.

Tomo 3. Buenos Aires: Imprenta y Casa Editora de Adolfo Grau, 1904.

Bunge, Alejandro E. Ferrocarriles argentinos. Contribución al estudio del patrimonio nacional. Buenos Aires: Imprenta Mercantil, 1918.

Ferrocarril Central Argentino. Apéndice del Reglamento General e Itinerario de Servicio. Departamento de Tráfico. Buenos Aires, 1922.

Ferrocarril Central de Córdoba. Reglamento del Telégrafo para Dirección y uso exclusivo de los Empleados de la Empresa. A regir desde el $1^{\circ}$ de Febrero de 1915.

- Reglamento general para el uso y gobierno de los empleados de la empresa solamente. Buenos Aires: Imprenta Cagnasso y Milone, 1915.

Ferrocarril Midland de Buenos Aires. Reglamento Interno. Buenos Aires: Imprenta "Victoria" de Anderson \& Co., 1911. 
Ferrocarril del Sud. Reglamento para el uso y gobierno de los empleados de la empresa solamente. En vigencia desde el 19 de noviembre de 1910.

Ministerio de Obras Públicas. Dirección General de Ferrocarriles. Estadística de los Ferrocarriles en Explotación. Tomo 24. Buenos Aires: Talleres Gráficos del Ministerio de Obras Públicas, 1920.

\section{Periódicos y revistas}

Boletín del Departamento Nacional del Trabajo (Buenos Aires) 1908, 1914, 1916.

Caras y Caretas (Buenos Aires) 1912, 1917.

El Obrero Ferroviario (Buenos Aires) 1912-1913, 1918, 1921.

La Época (Buenos Aires) 1916.

La Fraternidad (Buenos Aires) 1911, 1915, 1926.

La Prensa (Buenos Aires) 1904.

La Vanguardia (Buenos Aires) 1904.

Periódico de la Confederación General del Trabajo (CGT) (Buenos Aires) 1934.

Revista del Ferrocarril Central Argentino (Buenos Aires) 1915-1916, 1919, 1920.

The Economic Journal (Oxford) 1901.

\section{Bibliografía}

Argeri, María Elba. “'La peor plaga que pudo haber traído la locomotora’. Prostitución y control estatal en un Territorio Nacional Norpatagónico: Río Negro 1880-1920”. Anuario de Estudios Americanos 56.1 (1999): 217-235.

Badaloni, Laura. "La familia ferroviaria a principios del siglo XX: bienestar y lealtades de hierro en el Ferrocarril Central Argentino". Trabajadores $y$ empresarios en la Argentina del siglo XX: indagaciones desde la historia social. Comps. Daniel Dicósimo y Silvia Simonassi. Rosario: Prohistoria, 2011.

. "Huelga Ferroviaria de 1917. Violencia, complot maximalista y mujeres incendiarias". Imaginarios y prácticas de un orden burgués. Rosario, 1850-1930. Tomo 2. Dir. Marta Bonaudo. Rosario: Prohistoria, 2010.

Ballesteros Doncel, Esmeralda. "Poder de representación pública y discriminación de género. La prensa gráfica como productor de estereotipos de la feminidad". Ponencia, XII Congreso Español de Sociología, Universidad de Oviedo, 2016.

. "La construcción del empleo ferroviario como una profesión masculina, 1857-1962”. ¿Privilegios o eficiencia? Mujeres y hombres en los mercados de trabajo. Eds. Carmen Sarasúa y Lina Gálvez. San Vicente de Raspeig: Universidad de Alicante, 2003.

Barrancos, Dora. "La puñalada de Amelia (o cómo se extinguió la discriminación de las mujeres casadas del servicio telefónico en la Argentina)". 
Trabajos y Comunicaciones 8.34 (2008): 111-128.

Canali, Mariela. “¿Mujeres en el Ferrocarril?”. Historia Ferroviaria I. Jorge Tartarini y otros. Morón: Asociación de Amigos y Amigas del Instituto y Archivo Histórico Municipal de Morón, 2012.

Cena, Juan Carlos. El guardapalabras: memorias de un ferroviario. Buenos Aires: La Rosa Blindada, 1998.

Cobos Arteaga, Francisco de los. "Redescubrir los trabajos ocultos. Las empresas ferroviarias y la mano de obra femenina (1850-1900)". Revista Transportes, Servicios y Telecomunicaciones 33 (2017): 12-32.

D’Uva, Florencia. “Ayuda mutua, solidaridad gremial y género entre los trabajadores ferroviarios. Argentina, 1912-1917”. Boletín del Instituto de Historia Argentina y Americana "Dr. Emilio Ravignani” 51 (2019): 87-122.

. "Masculinidades obreras en los ferrocarriles: fuerza física, riesgos y responsabilidad profesional en la Argentina de principios del siglo XX”. Estudios del ISHIR 25 (2019): 1-22.

D’Uva, Florencia y Silvana A Palermo. "Vida sindical y sociabilidades masculinas: los trabajadores ferroviarios en la Argentina de principios del siglo XX". Archivos 7 (2015): 37-58.

Fernández, María Luisa. Coord. Las Flores, historias de la vida cotidiana (18561956). Tomo 2. La Plata: Instituto Cultural de la Provincia de Buenos Aires y Municipalidad de Las Flores, 2006.

Godoy, Solange. "El conflicto de las camareras del ferrocarril Mitre: tensiones en el mundo del trabajo ferroviario en contextos de reestructuración y modernización (Argentina, 1962-1964)". Revista Notas Históricas y Geográficas 24 (2020): 168-202.

Jepsen, Thomas C. My Sisters Telegraphic. Women in the Telgraph Office, 1846-1950. Ohio: Ohio University Press, 2000.

Lobato, Mirta Zaida. Historia de las trabajadoras en la Argentina (1869-1960). Buenos Aires: Edhasa, 2007.

Nari, Marcela. Políticas de maternidad y maternalismo político. Buenos Aires, 18901940. Buenos Aires: Biblos, 2004.

Palermo, Silvana A. "El derecho a mantener el hogar: las demandas obreras en la gran huelga ferroviaria desde una perspectiva de género. Argentina, 1917". Vivir con lo justo. Estudios de historia social del trabajo en perspectiva de género. Argentina, siglos XIX y XX. Andrea Andújar y otras. Rosario: Prohistoria, 2016.

. "En nombre del hogar proletario. Engendering the 1917 Great Railroad Strike in Argentina”. Hispanic American Historical Review 93.4 (2013): 585-620.

"Masculinidade, conflitos e solidariedades no mundo do trabalho ferroviário na Argentina (1912-1917)". Mundos do Trabalho 1.2 (2009): 94-123.

. “ ¿Trabajo masculino, protesta femenina? La participación de la mujer 
en la gran huelga ferroviaria de 1917". Historias de luchas, resistencias y representaciones. Mujeres en la Argentina, siglos XIX y XX. Comps. María Celia Bravo y otras. Tucumán: Editorial de la Universidad Nacional de Tucumán, 2007.

Queirolo, Graciela. Mujeres en las oficinas. Trabajo, género y clase en el sector administrativo (Buenos Aires, 1910-1950). Buenos Aires: Biblos, 2018.

Saus, María Alejandra. "Entre el ferrocarril y los prostíbulos: derrotero de una frágil urbanización". Registros 10 (2013): 112-127.

Tarullo, Raquel y Alfonsina Iacullo. Ferroviarios. Nuestra historia. Junín: Universidad Nacional Noroeste de la Provincia de Buenos Aires, 2013. 